\title{
ChemComm
}

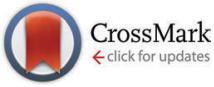

Cite this: Chem. Commun., 2016, 52,9972

\section{Correction: Beyond "turn-on" readout: from zero background to signal amplification by combination of magnetic separation and plasmon enhanced fluorescence}

\author{
Suqin Gong and Yunsheng Xia*
}

DOI: $10.1039 / c 6 c c 90336 c$

Correction for 'Beyond "turn-on" readout: from zero background to signal amplification by combination of magnetic separation and plasmon enhanced fluorescence' by Suqin Gong and Yunsheng Xia, Chem. Commun., 2016, 52, 9660-9663.

www.rsc.org/chemcomm

The authors regret that axis labels and units were omitted from the graphs in Fig. $2 \mathrm{C}$ and $\mathrm{F}$ in the original article, and the labels ' $\mathrm{C}$ ' and ' $\mathrm{F}$ ' are also missing from the respective parts of the image. A corrected version of Fig. 2 is presented herein.
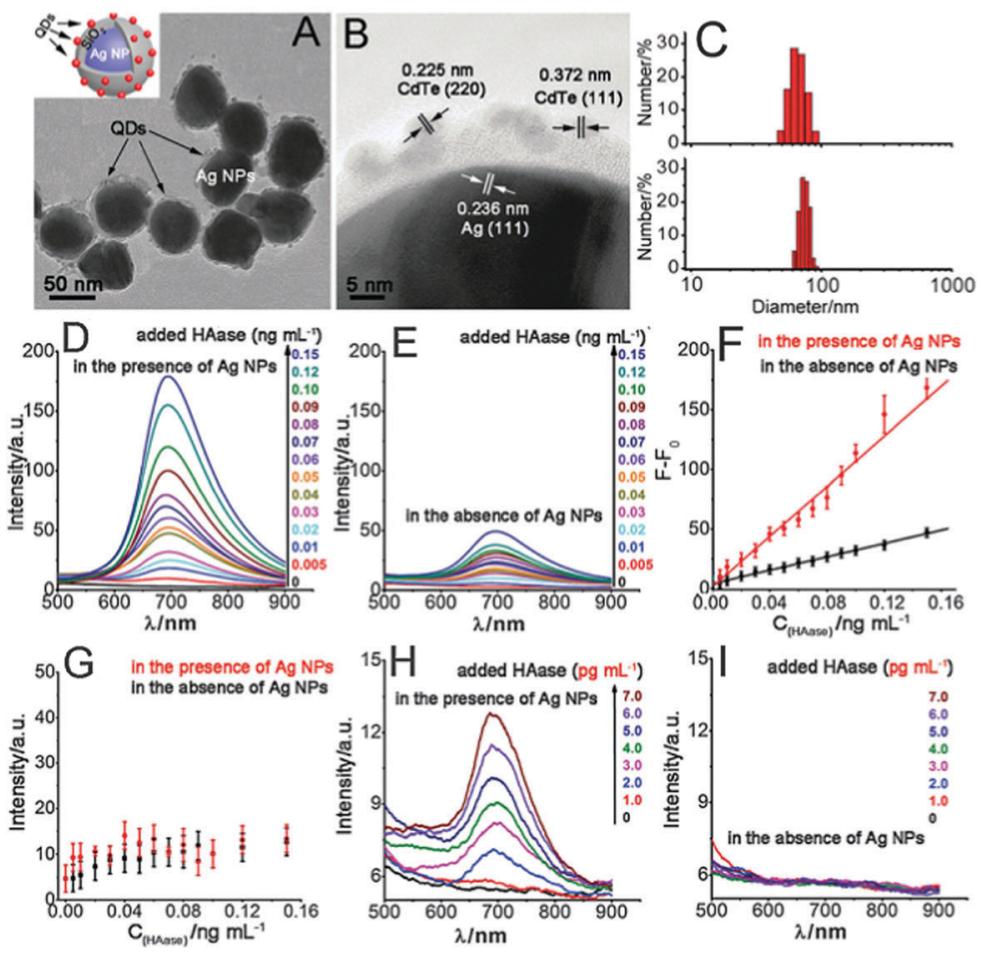

Fig. 2 TEM (A) and HRTEM (B) images of the hybrid (AgNP-QD) superstructures. (C) DLS sizes of the Ag NPs (top) and the hybrid AgNP-QD superstructures (bottom). Fluorescence emission spectra for assaying moderate concentrations of HAase $\left(0-0.15 \mathrm{ng} \mathrm{mL} \mathrm{L}^{-1}\right)$ in the presence $(\mathrm{D})$ and absence (E) of the Ag NPs. (F) Plots of the fluorescence intensities versus HAase concentrations in the presence and absence of the Ag NPs. (G) Plots of the scattering intensities (at $550 \mathrm{~nm}$ ) versus HAase concentrations in the presence and absence of Ag NPs. Fluorescence emission spectra for assaying ultra-trace concentrations of HAase $\left(0-7.0 \mathrm{pg} \mathrm{mL}^{-1}\right)$ in the presence $(\mathrm{H})$ and absence $(\mathrm{I})$ of the Ag NPs.

The Royal Society of Chemistry apologises for these errors and any consequent inconvenience to authors and readers. 